\title{
Personal or first-degree family breast cancer history: which has higher impact on tumor detection and tumor size in breast cancer
}

\author{
Fabienne Dominique Schwab - Nerbil Kilic - Dorothy Jane Huang • \\ Seraina Margaretha Schmid • Marcus Vetter • Andreas Schötzau • \\ Uwe Güth
}

Received: 28 May 2014/ Accepted: 9 December 2014/Published online: 17 December 2014 (C) Springer-Verlag Berlin Heidelberg 2014

\begin{abstract}
Purpose A woman's risk of developing breast cancer (BC) is increased if she has a personal history $(\mathrm{PH})$ or family history $(\mathrm{FH})$ of the disease. We compared the impact of the two risk factors $\mathrm{PH}$ and $\mathrm{FH}$ on tumor detection and tumor size at diagnosis in a cohort of $\mathrm{BC}$ patients.

Methods The study cohort comprised 1,037 invasive BC patients ( $\leq 70$ years at diagnosis). From these, 92 patients $(8.5 \%)$ had a positive $\mathrm{PH}$ and 151 patients $(13.7 \%)$ had a positive first-degree FH.
\end{abstract}

F. D. Schwab · D. J. Huang · U. Güth

Department of Gynecology and Obstetrics, University Hospital

Basel (UHB), Spitalstrasse 21, 4031 Basel, Switzerland

N. Kilic

Department of Oncology, Cantonal Hospital St. Gallen,

Rorschacher Strasse 95, 9007 St. Gallen, Switzerland

S. M. Schmid

Department of Gynecology and Obstetrics, Spital Grabs,

Spitalstrasse 44, 9472 Grabs, Switzerland

M. Vetter

Department of Oncology, UHB, Petersgraben 4, 4031 Basel,

Switzerland

\author{
A. Schötzau \\ Eudox Institute for Biomathematics, Malzgasse 9, 4052 Basel, \\ Switzerland \\ U. Güth $(\bowtie)$ \\ Department of Gynecology and Obstetrics, Cantonal Hospital \\ Winterthur, Brauerstrasse 15, 8401 Winterthur, Switzerland \\ e-mail: uwe.gueth@unibas.ch \\ U. Güth \\ Breast Center "SenoSuisse", Brauerstrasse 15, 8401 Winterthur, \\ Switzerland
}

Results Compared to the tumors of patients without $\mathrm{PH}$ or $\mathrm{FH}$, the lesions of patients who had a positive $\mathrm{PH}$ or a positive $\mathrm{FH}$ were more often found by radiologic breast examinations (RBE) (PH: $49.4 \%$, FH: $43.4 \%$, no PH/FH: $26.2 \%$; both comparisons $p<0.001$ ). In patients with a positive $\mathrm{FH}$, the tumors were slightly less often found by RBE as in patients with a positive PH $(p=0.468)$. Patients with a positive $\mathrm{PH}$ or $\mathrm{FH}$ had smaller tumors compared with those without such a history (PH: $19.7 \mathrm{~mm}$, FH: $19.6 \mathrm{~mm}$, no PH/FH: $26.7 \mathrm{~mm} ; p=0.015 / p<0.001$ ). The tumor sizes of patients with a positive $\mathrm{PH}$ were almost identical to those of patients with a positive $\mathrm{FH}$ $(p=0.999)$.

Conclusions In women with a positive $\mathrm{FH}$ or $\mathrm{PH}$ of $\mathrm{BC}$, the increased awareness of $\mathrm{BC}$ risk led to the detection of smaller tumors compared to women who have not had this experience. However, comparison of the two risk factors showed that they had a similar impact on the RBE detection rate of $\mathrm{BC}$ lesions and that the tumor sizes were nearly identical.

Keywords Breast cancer - Family history - Personal history - Detection method - Mammography screening . Tumor size

\section{Introduction}

It is universally recognized that a woman's risk of developing breast cancer (BC) is increased if she has a:

(a) Family history $(\mathrm{FH})$ of the disease $[1,2]$. In countries where $\mathrm{BC}$ is common, the cumulative incidence of $\mathrm{BC}$ up to the age of 80 is $13.3 \%$ for women with one affected first-degree relative and $21.1 \%$ for women with two [1]. For women without 
a known genetic predisposition for BC (i.e., BRCA 1 or BRCA 2), but who have a history of BC in a firstdegree relative, it has been suggested that screening mammography be initiated at an earlier age, particularly if the family member had $\mathrm{BC}$ at a younger age [3].

(b) Personal history $(\mathrm{PH})$ of $\mathrm{BC}$ [4-9].

Approximately $10-15 \%$ of patients undergoing breast-conserving therapy (BCT) for operable BC will develop a locoregional recurrence within 10 years [4, 5, 7-9]. In addition, BC survivors are also at a higher risk of developing a contralateral metachronous $\mathrm{BC}$; a current review found an incidence of $4 \%$ during an average follow-up of 7.5 years [6]. To account for these risks, annual surveillance mammography (i.e., mammography not indicated by clinical signs or symptoms) is a consensus-based recommendation for patients who were treated for primary $\mathrm{BC}[10,11]$.

This study evaluates and compares to what extent established radiological screening methods for BC detection were utilized in:

- $\mathrm{BC}$ patients with a positive $\mathrm{PH}$ of $\mathrm{BC}$.

- $\mathrm{BC}$ patients with a positive $\mathrm{FH}$ of $\mathrm{BC}$ (considered only women with first-degree $\mathrm{BC}$ affected relatives).

- In addition, we present data from a group of $\mathrm{BC}$ patients without a $\mathrm{PH}$ and first-degree $\mathrm{FH}$ of BC.

It has been widely demonstrated that personal and familial experiences with BC can influence individuals' behaviors to such an extent that the increased frequency of radiological examinations leads to earlier detection of the disease [2, 12-17].

To our knowledge, our study is the first comprehensive analysis comparing specifically the impact of both relevant risk factors $\mathrm{FH}$ and $\mathrm{PH}$ on tumor detection and tumor size. By doing so, we answer an up until now unanswered question: "Which personal factor has a higher impact on a more frequent tumor detection rate by radiologic examinations and leads more often to the diagnosis of smaller tumors: a positive family history or the woman's own history of breast cancer?"

\section{Patients and methods}

Data from the prospective relational Basel Breast Cancer Database (BBCD), which includes all newly diagnosed primary invasive $\mathrm{BC}$ cases treated at the University Women's Hospital Basel, Switzerland since 1990, provided the basis for this study. This institution comprises the largest $\mathrm{BC}$ center in the canton of Basel and is an adequate representation of the regional population. Within this database, disease-specific clinical and histopathological data, treatment characteristics, personal and family history as well as outcome data were recorded. For this study, data from female patients up to and including 2009, who were $\leq 70$ years at diagnosis, were analyzed. Since the goal of the study was to evaluate the impact of $\mathrm{FH}$ on tumor detection method and tumor size, 19 cases with inflammatory BC were excluded from further analysis. Due to the nature of inflammatory carcinomas, which arise rapidly, affect large parts of the breast, and often have no underlying definable mass, these cases are not suitable for evaluating tumor detection methods and tumor size. In total, our entire study cohort comprised 1,037 patients with 1,099 carcinomas (Table 1).

- Personal history group ( $n=92 ; 8.4 \%$ of the entire cohort): In total, 92 patients analyzed in this group had a history of invasive BC. In these cases, there was no distant metastatic disease known up until the diagnosis of the second malignancy (in nine cases, however, distant metastases were found during the staging examinations for the second $\mathrm{BC}$ ). In 61 patients, contralateral metachronous disease was diagnosed. In addition, we also considered 31 cases in which an ipsilateral non-inflammatory in-breast recurrence after previous breast-conserving surgery occurred.

- Family history group ( $n=151 ; 13.7 \%$ of the entire cohort): The criterion for a positive $\mathrm{FH}$ of $\mathrm{BC}$ was met when a patient reported one or more first-degree (mother, sister, daughter) affected relatives. Table 2 lists the number of relatives with a history of $\mathrm{BC}$ and the age group of the affected relative at the time that her $\mathrm{BC}$ was diagnosed.

In 17 cases, the patients had both a positive $\mathrm{PH}$ and a positive $\mathrm{FH}$; we placed these patients in the "personal history"-category.

- Control group ( $n=856 ; 77.9 \%$ of the entire cohort): These patients had neither a PH of BC nor any firstdegree $\mathrm{BC}$ affected relatives.

\section{Clinicopathological data}

The following data were available for all patients: age at initial diagnosis, histological subtype, grading, hormonal receptor (HR) status, tumor stage according to the American Joint Committee on Cancer (AJCC)/International Union Against Cancer (UICC) TNM Classification; because HER-2 status has been routinely assessed for all patients since 2002, we included data from 2002 to 2009 only in the analysis of this particular characteristic. 
Table 1 Comparison between a cohort of 1,099 cases of breast cancer patients ( $\leq 70$ years) with and without personal and family history of breast cancer

\begin{tabular}{|c|c|c|c|}
\hline Variable & $\begin{array}{l}\text { Personal } \\
\text { history } \\
n=92(\%)\end{array}$ & $\begin{array}{l}\text { Family } \\
\text { history } \\
n=151 \\
(\%)\end{array}$ & $\begin{array}{l}\text { No BC } \\
\text { history } \\
n=856 \\
(\%)\end{array}$ \\
\hline \multicolumn{4}{|l|}{ Age (years) } \\
\hline Mean & $58.7^{\mathrm{a}}$ & 54.9 & 54.3 \\
\hline Median & $59^{\mathrm{a}}$ & 56 & 55 \\
\hline \multicolumn{4}{|l|}{ Tumor detection method } \\
\hline Breast self-examination & $39(42.8)$ & $73(49.6)$ & $517(61.6)$ \\
\hline $\begin{array}{l}\text { Radiologic breast } \\
\text { examination }\end{array}$ & $38(41.8)$ & $56(38.1)$ & $184(21.9)$ \\
\hline $\begin{array}{l}\text { Clinical breast } \\
\text { examination }\end{array}$ & $14(15.4)$ & 17 (11.6) & $127(15.1)$ \\
\hline Other method & - & $1(0.7)$ & $12(1.4)$ \\
\hline Unknown & 1 & 4 & 16 \\
\hline \multicolumn{4}{|l|}{ Tumor size (mm) } \\
\hline Mean & 19.7 & 19.6 & 26.7 \\
\hline Median (range) & $\begin{array}{l}16.5 \\
(\leq 1-125)\end{array}$ & ${ }_{(\leq 1-115)}$ & $20(0-220)$ \\
\hline \multicolumn{4}{|l|}{ Tumor category } \\
\hline $\mathrm{T} 0$ & - & - & $2(0.2)$ \\
\hline $\mathrm{T} 1$ & $62(67.4)$ & $102(67.5)$ & $439(51.3)$ \\
\hline $\mathrm{T} 2$ & $24(26.1)$ & $42(27.8)$ & $316(36.9)$ \\
\hline $\mathrm{T} 3$ & $5(5.4)$ & $3(2.0)$ & $68(8.0)$ \\
\hline Non-inflammatory T4 & $1(1.1)$ & $4(2.7)$ & $31(3.6)$ \\
\hline $\begin{array}{l}\text { Bilateral synchronous } \\
\text { carcinoma }\end{array}$ & - & $3(2.0)$ & $17(2.0)$ \\
\hline \multicolumn{4}{|l|}{ AJCC/UICC TNM stage } \\
\hline I & $52(56.5)$ & $76(50.3)$ & $308(36.0)$ \\
\hline II & $24(26.1)$ & $50(33.1)$ & $350(40.9)$ \\
\hline III & $7(7.6)$ & $21(13.9)$ & $156(18.2)$ \\
\hline IV & $9(9.8)$ & $4(2.7)$ & $42(4.9)$ \\
\hline \multicolumn{4}{|l|}{ Histologic subtype } \\
\hline Ductal invasive & 77 (83.7) & $107(71.8)$ & $658(77.3)$ \\
\hline Lobular invasive & $12(13.0)$ & $28(18.8)$ & $106(12.5)$ \\
\hline Rare types & $3(3.3)$ & $14(9.4)$ & $87(10.2)$ \\
\hline Not available & - & 2 & 5 \\
\hline \multicolumn{4}{|l|}{ Grading } \\
\hline $\mathrm{G} 1 / 2$ & $40(46.5)$ & $100(69.4)$ & $438(54.4)$ \\
\hline G3 & $46(53.5)$ & $44(30.6)$ & $367(45.6)$ \\
\hline Not available & 6 & 7 & 51 \\
\hline \multicolumn{4}{|l|}{ Hormonal receptor status } \\
\hline Positive & $67(78.8)$ & $129(87.2)$ & $669(81.2)$ \\
\hline Negative & $18(21.2)$ & $19(12.8)$ & $155(18.8)$ \\
\hline Not available & 7 & 3 & 32 \\
\hline HER2 status, 2002-2009 & $n=45$ & $n=79$ & $n=370$ \\
\hline Positive & $12(26.7)$ & $8(10.3)$ & $66(18.0)$ \\
\hline Not available & - & 1 & 3 \\
\hline Triple-negative subtype & 7 (15.6) & $4(5.1)$ & $50(13.6)$ \\
\hline
\end{tabular}

AJCC American Joint Committee on Cancer; UICC International Union Against Cancer (LIT)

a Analysis of patient's age: metachronous BC $(n=61)$ was included; local recurrence $(n=31)$ was excluded
Table 2 Family history $(n=151)$ : number of affected relatives, and age of the affected relative at the time that her $\mathrm{BC}$ was diagnosed

\begin{tabular}{ll}
\hline Characteristic & $n(\%)$ \\
\hline FH & $65(43.3)$ \\
Relative diagnosed before age 50 & $85(56.7)$ \\
Relative diagnosed $\geq 50$ years & 1 \\
Relative's age unknown & $134(88.7)$ \\
One first-degree relative affected with BC & $16(10.6)$ \\
Two first-degree relatives affected with BC & $1(0.7)$ \\
Three first-degree relatives affected with BC & 1.1 \\
Mean number & \\
PH & $51(55.4)$ \\
Tumor size of the first tumor: $\leq 20$ mm & $41(44.6)$ \\
Tumor size of the first tumor: $>20$ mm & $46(50.0)$ \\
Period between 1 st and 2nd lesion: $<72$ months & $46(50.0)$ \\
Period between 1st and 2nd lesion: $\geq 72$ months &
\end{tabular}

Personal history $(n=91)$ : tumor size of the first tumor, and period between the primary and the second lesion

$F H$ family history, $P H$ personal history, $B C$ breast cancer

\section{Tumor size}

For most of the cases analyzed ( $n=943,93.6 \%$ ), the size of the primary tumor was measured during pathological examination of the surgically resected lesion. In 40 patients (4.0\%; positive FH: $n=4$, negative $\mathrm{PH} / \mathrm{FH}: n=36$ ), who received neoadjuvant therapy, the pre-therapeutic clinically assessed tumor sizes were used. This was also the case for 24 patients $(2.4 \%$; positive $\mathrm{PH}: n=2$; positive $\mathrm{FH}$ : $n=1$; negative PH/FH: $n=21$ ) in whom no surgery was performed.

Of the entire study cohort, 20 patients presented with synchronous bilateral BC $(2.0 \%)$; of these cases, the tumor with the more advanced tumor size ("reference lesion") was considered for analysis.

Tumor detection method

The following two methods were analyzed:

1. Breast self-examination (BSE), $n=629$ (57.2\%).

2. Radiological breast examination (RBE), $n=278$ $(25.3 \%)$.

Cases in which the tumor was found by a physician during a clinical breast examination [CBE, $n=158$ $(14.4 \%)$ ] were not considered in the diagnostic method analysis because, contrary to BSE and the utilization of RBE, CBE does not necessarily reflect the patient's awareness of early BC detection. The following patients were also excluded from this part of analysis: 13 patients $(1.2 \%)$ with BC detected by other methods 
than the three mentioned above, and 21 patients $(1.9 \%)$ who lacked documentation of the tumor detection method.

Data collection methods and study design were approved by the Ethics Committee of the University of Basel.

\section{Statistical methods}

Comparisons between nominal parameters were made using the Fisher's exact test. In the case of metric variables, $t$ test or paired $t$ test was performed as appropriate. To predict age and tumor size, univariate linear regression analysis was performed. Results are presented as differences of means (MD) with corresponding $95 \%$ confidence intervals $(95 \% \mathrm{CI})$ and $p$ values. In the case of the binary dependent variable (detection method), logistic regressions were performed. Results are presented as odds ratios (OR) with the corresponding $95 \% \mathrm{CI}$ and $p$ values. In all statistical tests, the level of significance was $p<0.05$. All evaluations were performed with $\mathrm{R}$ Development Core Team software, version 13.1. The study is exploratory; therefore, no adjustments for multiple comparisons were done.

\section{Results}

\section{Personal history}

For patients who had metachronous BC or ipsilateral intramammary recurrence, the median interval between primary diagnosis and the second event was 71.5 months (range 3-324 months). The median tumor size at first diagnosis was $20 \mathrm{~mm}$ (mean $21.9 \mathrm{~mm}$, range 1-68 mm) and the median tumor size of the second $\mathrm{BC}$ event was $16.5 \mathrm{~mm}$ (mean $19.7 \mathrm{~mm}$, range $<1-125 \mathrm{~mm}$ ); the paired $t$ test showed no significant difference (MD 2.16, $95 \%$ CI $2.05-6.38, p=0.311)$. A comparison between tumor sizes of the primary and the second lesion showed the following results:

- In 38 cases $(41.3 \%)$, the second lesion was at least $5 \mathrm{~mm}$ smaller than the primary tumor,

- In 35 cases $(38.0 \%)$, the tumors were of similar size $( \pm 5 \mathrm{~mm})$

- In 19 cases $(20.7 \%)$, the second lesion was at least $5 \mathrm{~mm}$ larger than the primary tumor.

Patients with a positive PH were with 58.7 years significantly older when compared both with the patients who had a FH and the group without a BC history $(p=0.004$ for both variables; Tables 1,3 ).
Tumor detection method: radiological breast examination vs. breast self-examination (Tables 1,4 )

Compared to the tumors of patients without $\mathrm{PH}$ or $\mathrm{FH}$, the lesions of patients who had a positive $\mathrm{PH}$ were more often found by RBE (49.4 vs. $26.2 \%$; OR 2.63, $95 \%$ CI $1.64-4.35, p<0.001$; Table 4); a similar result was found in the comparison between patients without $\mathrm{PH} / \mathrm{FH}$ and those with a positive $\mathrm{FH}$, which also reached statistical significance (43.4 vs. $26.2 \%$; OR 2.12, $95 \%$ CI $1.45-3.13, p<0.001)$. In patients with a positive $\mathrm{FH}$, the tumors were less often found by RBE as in patients with a $\mathrm{PH}$; this, however, failed to reach statistical significance (43.4 vs. $49.4 \%$, OR $1.24,95 \%$ CI $0.70-2.19, p=0.468$ ).

Within the group of patients with a positive $\mathrm{FH}$, the number of affected relatives had impact on the detection rate of tumors by RBE: having more than one affected relative was associated with more frequent detection by RBE ( 1 affected relative: $40.2 \%$ vs. $\geq 1$ affected relative: $75.0 \%, p=0.030$; Table 4$)$. The age of the affected relative at the time that her BC was diagnosed was not relevant $(p=0.285)$. Within the group of patients with a positive $\mathrm{PH}$, the length of time between the primary and the second lesion $(p=0.651)$ and the size of the first tumor $(p=1.00)$ were no significant factors which led that the second $\mathrm{BC}$ was more often found by RBE.

Tumor size (Tables 1,5$)$

Patients with a positive $\mathrm{PH}$ or a FH had smaller tumors at diagnosis compared with those without such a history (PH: 19.7 vs. $26.7 \mathrm{~mm}$; MD 7.0, $95 \%$ CI $4.5-9.5, p=0.015$. FH: 19.6 vs. $26.7 \mathrm{~mm}$; MD 7.1, $95 \%$ CI 5.1-9.1, $p<0.001$; Table 5). The tumor sizes of patients with a positive $\mathrm{PH}$ were almost identical to those of patients with a positive FH (19.7 vs. $19.6 \mathrm{~mm}, p=0.999$ ).

Within the group of patients with a positive $\mathrm{FH}$, neither the number of affected relatives ( $p=0.235$; Table 5$)$ nor the

Table 3 Patient's age according to family and personal history of BC

\begin{tabular}{lll}
\hline & MD $(95 \% \mathrm{CI})$ & $p$ value \\
\hline (0) no FH/PH: 54.3 years & & \\
(1) FH: 54.9 years & & \\
(2) PH: 58.7 years & & $\mathbf{0 . 0 0 6}$ \\
Overall & & 0.794 \\
0 vs. 1 & $-0.6(-1.5,0.3)$ & $\mathbf{0 . 0 0 4}$ \\
0 vs. 2 & $-4.3(-5.7,-2.9)$ & $\mathbf{0 . 0 0 4}$ \\
1 vs. 2 & $-3.7(-5.3,-2.19)$ &
\end{tabular}

Bold values are statistically significant at $p<0.05$

$M D$ mean difference, $C I$ confidence interval, $F H$ family history, $P H$ personal history, $B C$ breast cancer 
Table 4 Tumor detection method (radiological examination vs. selfexamination) according to family and personal history of breast cancer

\begin{tabular}{|c|c|c|}
\hline & OR $(95 \% \mathrm{CI})$ & $p$ value \\
\hline \multicolumn{3}{|c|}{ (0) no FH/PH $(n=856)$} \\
\hline \multicolumn{3}{|c|}{$\begin{array}{l}\text { RBE: } n=184(26.2 \%) ; \text { SE: } n=517 \\
\quad(73.8 \%)\end{array}$} \\
\hline \multicolumn{3}{|c|}{ (1) $\mathrm{FH}(n=151)$} \\
\hline \multicolumn{3}{|c|}{$\begin{array}{l}\text { RBE: } n=56(43.4 \%) ; \text { SE: } n=73 \\
\quad(56.6 \%)\end{array}$} \\
\hline \multicolumn{3}{|c|}{ (2) $\mathrm{PH}(n=92)$} \\
\hline \multicolumn{3}{|c|}{$\begin{array}{l}\text { RBE: } n=38(49.4 \%) ; \text { SE: } n=39 \\
\quad(50.6 \%)\end{array}$} \\
\hline \multicolumn{2}{|c|}{ Overall } & $<0.001$ \\
\hline 0 vs. 1 & $\begin{array}{l}2.12(1.45 \\
3.13)\end{array}$ & $<0.001$ \\
\hline 0 vs. 2 & $\begin{array}{l}2.63(1.64 \\
4.35)\end{array}$ & $>0.001$ \\
\hline 1 vs. 2 & $\begin{array}{l}1.24 \\
(0.70-2.19)\end{array}$ & 0.468 \\
\hline \multicolumn{3}{|c|}{ (1) $\mathrm{FH}(n=151)$} \\
\hline \multicolumn{3}{|c|}{ Number of affected relatives } \\
\hline \multicolumn{3}{|c|}{$\begin{array}{l}1 \text { affected relative, } n=134 \text { vs. } \geq 1 \text { affected relative, } \\
n=17\end{array}$} \\
\hline RBE: & & $\mathbf{0 . 0 3 0}$ \\
\hline \multicolumn{3}{|c|}{$\begin{array}{l}\text { Age of the affected relative at the time that her } \mathrm{BC} \text { was diagnosed } \\
<50 \text { years, } n=65 \text { vs. } \geq 50 \text { years, } n=85\end{array}$} \\
\hline \multicolumn{3}{|c|}{ (2) $\mathrm{PH}(n=92)$} \\
\hline \multicolumn{3}{|c|}{ Period between the primary and the second lesion } \\
\hline RBE: & & 0.651 \\
\hline \multicolumn{3}{|c|}{ Size of the first tumor } \\
\hline \multicolumn{3}{|c|}{$\leq 20 \mathrm{~mm}, n=51$ vs. $>20 \mathrm{~mm}, n=41$} \\
\hline RBE: & $(48.5 \%)$ & 1.00 \\
\hline
\end{tabular}

Bold values are statistically significant at $p<0.05$

$O R$ odds ratio, $C I$ confidence interval, $F H$ family history, $P H$ personal history, $B C$ breast cancer, $R B E$ radiological breast examination, $S E$ self-examination

age at which the affected relative was diagnosed with $\mathrm{BC}$ ( $p=0.622)$ correlated with tumor size. For the patients with a positive $\mathrm{PH}$, no significant correlations were found with the length of time between the primary and the second lesion $(p=0.224)$ and the size of the first tumor $(p=0.848)$.

In the subgroup of patients who found their tumors by self-examination (BSE), patients with either a positive FH or $\mathrm{PH}$ found smaller lesions than patients with no history (no PH/FH: $30.8 \mathrm{~mm}$; FH: $23.1 \mathrm{~mm}$; PH: $26.1 \mathrm{~mm}$ ); a statistically significant difference, however, was only found in the comparison between the "no $\mathrm{PH} / \mathrm{FH}$ " group and patients with a positive FH (MD -7.4, $95 \%$ CI 7.8-11.3, $p=0.038$; Table 5). There was no significant difference in
Table 5 Tumor size according to family and personal history of breast cancer

MD $(95 \% \mathrm{CI}) \quad p$ value

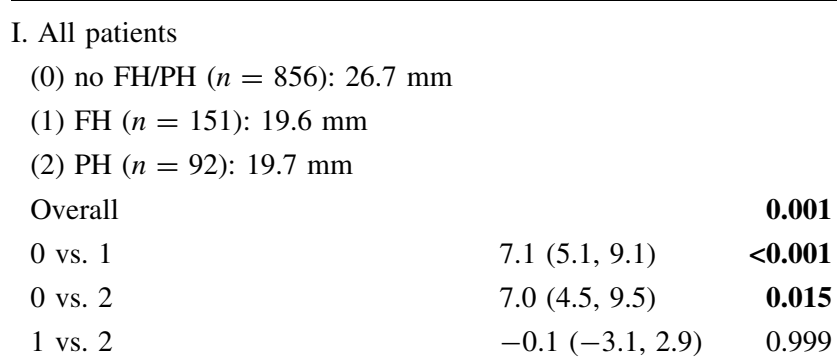

(1) $\mathrm{FH}$

Number of affected relatives

1 affected relative, $n=134$ vs. $\geq 1$ affected relative,

$n=17$

Median tumor size: 19.9 vs. $16.9 \mathrm{~mm}$

Age of the affected relative at the time that her BC was diagnosed $<50$ years, $n=65$ vs. $\geq 50$ years, $n=85$

Median tumor size: 18.6 vs. $20.3 \mathrm{~mm}$

(2) $\mathrm{PH}$

Period between the primary and the second lesion

$<72$ months, $n=46$ vs. $\geq 72$ months, $n=46$

Median tumor size: 21.9 vs. $17.6 \mathrm{~mm}$

Size of the first tumor

$\leq 20 \mathrm{~mm}, \mathrm{n}=51$ vs. $>20 \mathrm{~mm}, \mathrm{n}=41$

Median tumor size: 19.4 vs. $20.1 \mathrm{~mm}$

0.848

II. Tumors found by self-examination

(0) no FH/PH $(n=517): 30.8 \mathrm{~mm}$

(1) $\mathrm{FH}(n=73): 23.1 \mathrm{~mm}$

(2) $\mathrm{PH}(n=39): 26.1 \mathrm{~mm}$

Overall

$\mathbf{0 . 0 3 4}$

0 vs. 1

$8.0(4.8,11.3)$

0.038

0 vs. 2

$4.7(0.4,9.0)$

0.524

1 vs. 2

$-3.2(-8.5,1.9)$

0.797

Bold values are statistically significant at $p<0.05$

I. All patients, II. Tumors found by self-examination

$M D$ mean difference, $C I$ confidence interval, $F H$ family history, $P H$ personal history

the size of self-detected tumors in patients with a positive $\mathrm{PH}$ compared to those with a positive $\mathrm{FH}(p=0.797)$.

\section{Discussion}

Not surprisingly, our data demonstrate that BC patients who had a positive $\mathrm{PH}$ or FH show distinct differences with regard to tumor detection and tumor size at diagnosis when compared to a group of patients without such a history: in patients with a positive $\mathrm{PH}$ or $\mathrm{FH}$, the tumors were more often found by RBE and were significantly smaller. 
However, returning to our main question, "Which personal factor has a higher impact on tumor detection rate by radiologic examinations and leads more often to the diagnosis of smaller tumors: a positive family history or the woman's own history of breast cancer?", our data show that both situations have a similar effect. The tumors of BC patients with a positive $\mathrm{PH}$ were more often diagnosed by radiological examinations; patients with a positive $\mathrm{FH}$ obviously developed a slightly higher body awareness and tended to detect their tumors (self-examination) at a smaller size. Both factors seemed to be of approximately equal weight, such that the tumor sizes found in both groups were nearly identical (PH: $19.7 \mathrm{~mm}$; $\mathrm{FH}$ : $19.6 \mathrm{~mm})$.

There are particular factors which must be considered in the interpretation of our findings:

\section{Family history}

As inclusion criterion for a positive $\mathrm{FH}$, we only included patients who had a first-degree relative with $\mathrm{BC}$. We did not include patients with more distantly related $\mathrm{BC}$ affected relatives in the FH group because we showed in a previously published study [15] that, in BC patients who had only second-degree relatives, the tumors were diagnosed similarly often by RBE and were of a similar size compared to BC patients without a positive $\mathrm{FH}$. These results were in line with data from other studies [18, 19].

In this study, $15.3 \%$ of the entire cohort of BC patients diagnosed in a 20 -year period had first-degree relatives with a history of BC (however, we included 17 patients who had both a positive FH and PH in the "PH group"). Our data are approximately comparable with that from the Collaborative Group on Hormonal Factors in Breast Cancer (this project analyzed 52 epidemiological studies with a total of 58,209 BC patients) in which $12.9 \%$ of women with $\mathrm{BC}$ had first-degree relatives with a history of BC [1]. We deliberately did not consider BRCA1/BRCA2 mutation carriers separately. First, our study covers a 20 -year period and during the first decade of this period hereditary BRCA1/2-related BC was not yet a focus of interest. Second, due to the infrequent nature of BRCA1/BRCA2 mutations, even in women with a first-degree history, these mutations do not play an important role in the general behavior of women regarding mammography screening [19].

Radiological breast examination

In patients who had local recurrence, the rate of detection by mammography varied in the literature and ranged from 32 to $66 \%$, whereas the clinical detection rate ranged from 33 to $41 \%[13,19]$. In our cohort, the rate of recurrent ipsilateral and contralateral metachronous tumors found by RBE was approximately $42 \%$; the rate of tumors found by the patients themselves was almost identically high. On the one hand, this is a disappointing finding regarding the usefulness of breast imaging in women with a high risk of developing subsequent $\mathrm{BC}$ lesions. On the other hand, it shows that both radiologic and clinical examination are important factors for the detection of tumors in patients with a personal BC history [20] and thus patients should be encouraged to feel and look for changes in their breasts and should not only rely on radiologic examinations during their BC follow-up. Since some studies showed that survival was improved when recurrence was found by mammography instead of physical examination [13, 21, 22], the detection rate of $\mathrm{BC}$ recurrence through better reading and technique of mammograms will hopefully also increase.

Several studies reported an underuse of surveillance mammography for follow-up among women diagnosed with BC. Typically, the percentage of women having mammograms decreases over time. Doubeni et al. [23] reported that during the fifth year after BC treatment only $63 \%$ of the patients had mammograms; Keating et al. [24] reported that approximately $57 \%$ had mammography yearly over 3 years. We do not have exact information regarding the use of mammography surveillance during BC follow-up in our cohort. However, we estimate that approximately $70 \%$ of the patients analyzed in this study adhered to the guidelines and underwent annual surveillance mammography.

Our study confirms previously published data [19], which demonstrated that in a cohort of $\mathrm{BC}$ patients, the tumors of women who had a positive $\mathrm{FH}$ for $\mathrm{BC}$ were more often found by RBE compared to women who had no BC affected relatives. This might result from the fact that women with a family BC history, obviously influenced by personal and familial experiences with $\mathrm{BC}$, generally use $\mathrm{BC}$ screening more often than women without such history $[2,12-15]$. It is not possible to determine precisely to what extent the higher motivation for mammography can be attributed to the women's own initiative, the direct influence of family members (e.g., mother-daughter communication) or the motivating influence of their doctors who are aware of the positive $\mathrm{FH}$ and incorporate this information into their mammography referral practices.

Mammography screening in the study cohort

In the canton of Basel and the adjoining region of Northwestern Switzerland, there was no publicly funded organized mammography screening program during the study period. All interested and motivated women, however, had free access to mammography. In such an environment, the utilization of $\mathrm{RBE}$ for early $\mathrm{BC}$ detection is strongly 
dependent on the women's motivation and own initiative (opportunistic screening) as well as the recommendation by her physician. For the purpose of our study, i.e., to test whether the knowledge and experience of $\mathrm{BC}$ in the family increases $\mathrm{BC}$ awareness, a patient-driven screening setting was better suited than a general screening setting.

\section{Breast self-examination}

Our results confirm the findings of recent studies, which showed that women with affected first-degree relatives were more likely to have smaller carcinomas and more often early disease stage $[18,19,25]$. The phenomenon that patients with positive $\mathrm{FH}$ and $\mathrm{PH}$ had smaller tumors at diagnosis might be explained by more diligent use of BC screening amongst women who considered themselves to be at increased risk of developing the disease. However, we also observed this phenomenon in patients who detected their tumors by self-examination. In these cases, the personal experience of having a close family member with $\mathrm{BC}$ was so influential that they became more aware of the necessity of self-examination and perceived changes earlier, thus leading to the identification of smaller tumors.

\section{Conclusions}

Obviously, many women with a first-degree relative affected by $\mathrm{BC}$ and women with a positive $\mathrm{PH}$ of $\mathrm{BC}$ have been sufficiently touched by that experience. In cases when these patients developed a $\mathrm{BC}$, this increased awareness of $\mathrm{BC}$ risk led to the detection of smaller tumors compared to women who have not had this experience. However, comparison of the two risk factors showed that they had a similar impact on the RBE detection rate of $\mathrm{BC}$ lesions and that the tumor sizes were nearly identical.

Conflict of interest The authors declare that there are no financial or personal relationships with other people or organizations that could inappropriately influence the work reported or the conclusions, implications, or opinions stated.

\section{References}

1. Collaborative Group on Hormonal Factors in Breast Cancer (2001) Familial breast cancer: collaborative reanalysis of individual data from 52 epidemiological studies including 58,209 women with breast cancer and 101,986 women without the disease. Lancet 358(9291):1389-1399

2. Colditz GA, Kaphingst KA, Hankinson SE, Rosner B (2012) Family history and risk of breast cancer: nurses' health study. Breast Cancer Res Treat 133(3):1097-1104

3. Kerlikowske K, Carney PA, Geller B, Mandelson MT, Taplin SH, Malvin K, Ernster V, Urban N, Cutter G, Rosenberg R et al (2000) Performance of screening mammography among women with and without a first-degree relative with breast cancer. Ann Int Med 133(11):855-863

4. Darby S, McGale P, Correa C, Taylor C, Arriagada R, Clarke M, Cutter D, Davies C, Ewertz M, Godwin J et al (2011) Effect of radiotherapy after breast-conserving surgery on 10-year recurrence and 15-year breast cancer death: meta-analysis of individual patient data for 10,801 women in 17 randomised trials. Lancet 378(9804): 1707-1716

5. Fisher B, Anderson S, Bryant J, Margolese RG, Deutsch M, Fisher ER, Jeong JH, Wolmark N (2002) Twenty-year follow-up of a randomized trial comparing total mastectomy, lumpectomy, and lumpectomy plus irradiation for the treatment of invasive breast cancer. N Engl J Med 347(16):1233-1241

6. Nichols HB, Berrington de Gonzalez A, Lacey JV Jr, Rosenberg PS, Anderson WF (2011) Declining incidence of contralateral breast cancer in the United States from 1975 to 2006. J Clin Oncol 29(12):1564-1569

7. van Laar C, van der Sangen MJ, Poortmans PM, Nieuwenhuijzen GA, Roukema JA, Roumen RM, Tjan-Heijnen VC, Voogd AC (2013) Local recurrence following breast-conserving treatment in women aged 40 years or younger: trends in risk and the impact on prognosis in a population-based cohort of 1143 patients. Eur J Cancer 49(15):3093-3101

8. Wapnir IL, Anderson SJ, Mamounas EP, Geyer CE Jr, Jeong JH, Tan-Chiu E, Fisher B, Wolmark N (2006) Prognosis after ipsilateral breast tumor recurrence and locoregional recurrences in five National Surgical Adjuvant Breast and Bowel Project nodepositive adjuvant breast cancer trials. J Clin Oncol 24(13):2028-2037

9. Yang SH, Yang KH, Li YP, Zhang YC, He XD, Song AL, Tian JH, Jiang L, Bai ZG, He LF et al (2008) Breast conservation therapy for stage I or stage II breast cancer: a meta-analysis of randomized controlled trials. Ann Oncol 19(6):1039-1044

10. Khatcheressian JL, Hurley P, Bantug E, Esserman LJ, Grunfeld E, Halberg F, Hantel A, Henry NL, Muss HB, Smith TJ et al (2013) Breast cancer follow-up and management after primary treatment: American Society of Clinical Oncology clinical practice guideline update. J Clin Oncol 31(7):961-965

11. Aebi S, Davidson T, Gruber G, Cardoso F (2011) Primary breast cancer: ESMO Clinical Practice Guidelines for diagnosis, treatment and follow-up. Ann Oncol 22(Suppl 6)):vi12-vi24

12. Couto E, Banks E, Reeves G, Pirie K, Beral V (2008) Family history and breast cancer tumour characteristics in screened women. Int J Cancer 123(12):2950-2954

13. Montgomery DA, Krupa K, Cooke TG (2007) Follow-up in breast cancer: does routine clinical examination improve outcome? A systematic review of the literature. Br Journal Cancer 97(12):1632-1641

14. Murabito JM, Evans JC, Larson MG, Kreger BE, Splansky GL, Freund KM, Moskowitz MA, Wilson PW (2001) Family breast cancer history and mammography: Framingham Offspring Study. Am J Epidemiol 154(10):916-923

15. Schwab FD, Burki N, Huang DJ, Heinzelmann-Schwarz V, Schmid SM, Vetter M, Schotzau A, Guth U (2014) Impact of breast cancer family history on tumor detection and tumor size in women newly-diagnosed with invasive breast cancer. Fam Cancer 13:99-107

16. Taplin S, Anderman C, Grothaus L (1989) Breast cancer risk and participation in mammographic screening. Am J Public Health 79(11):1494-1498

17. Tracy KA, Quillin JM, Wilson DB, Borzelleca J, Jones RM, McClish D, Bowen D, Bodurtha J (2008) The impact of family history of breast cancer and cancer death on women's mammography practices and beliefs. Genet Med 10(8):621-625

18. Lijovic M, Davis SR, Fradkin P, Bradbury J, La China M, Schwarz M, Wolfe R, Farrugia H, Bell RJ (2009) The relationship 
between knowledge of family history and cancer characteristics at diagnosis in women newly-diagnosed with invasive breast cancer. Fam Cancer 8(4):299-305

19. Malone KE, Daling JR, Doody DR, O'Brien C, Resler A, Ostrander EA, Porter PL (2011) Family history of breast cancer in relation to tumor characteristics and mortality in a populationbased study of young women with invasive breast cancer. Cancer Epidemiol Biomarkers Prev 20(12):2560-2571

20. Chen C, Orel SG, Harris EE, Hwang WT, Solin LJ (2003) Relation between the method of detection of initial breast carcinoma and the method of detection of subsequent ipsilateral local recurrence and contralateral breast carcinoma. Cancer 98(8):1596-1602

21. Lu WL, Jansen L, Post WJ, Bonnema J, Van de Velde JC, De Bock GH (2009) Impact on survival of early detection of isolated breast recurrences after the primary treatment for breast cancer: a meta-analysis. Breast Cancer Res Treat 114(3):403-412
22. Montgomery DA, Krupa K, Jack WJ, Kerr GR, Kunkler IH, Thomas J, Dixon JM (2007) Changing pattern of the detection of locoregional relapse in breast cancer: the Edinburgh experience. Br J Cancer 96(12):1802-1807

23. Doubeni CA, Field TS, Ulcickas Yood M, Rolnick SJ, Quessenberry CP, Fouayzi H, Gurwitz JH, Wei F (2006) Patterns and predictors of mammography utilization among breast cancer survivors. Cancer 106(11):2482-2488

24. Keating NL, Landrum MB, Guadagnoli E, Winer EP, Ayanian JZ (2006) Factors related to underuse of surveillance mammography among breast cancer survivors. J Clin Oncol 24(1):85-94

25. Molino A, Giovannini M, Pedersini R, Frisinghelli M, Micciolo R, Mandara M, Pavarana M, Cetto GL (2004) Correlations between family history and cancer characteristics in 2256 breast cancer patients. Br J Cancer 91(1):96-98 